\title{
Produtores Familiares e Estratégias Ligadas à Terra
}

\author{
Antonio Lázaro Sant ${ }^{\prime}$ Ana ${ }^{1}$ \\ Vera Mariza Henriques de Miranda Costa ${ }^{2}$
}

Resumo: A manutenção e/ou a ampliação da terra compõem o eixo central em torno do qual os produtores familiares organizam sua vida e seu trabalho. Este artigo analisa as estratégias desses produtores em relação à divisão de herança e à sucessão, e as formas que utilizam para aquisição de novas áreas. O levantamento das características das famílias e da propriedade foi realizado por meio de um questionário aplicado junto a 89 produtores familiares de três municípios da mesorregião de São José do Rio Preto (SP). Posteriormente foi entrevistado um terço dos produtores de cada município que havia respondido ao questionário. A análise das estratégias fundiárias mostrou uma grande diversidade na forma de partilhar a herança e de conduzir a sucessão, sendo que ambos os processos são apoiados, basicamente, em regras tradicionais, embora mantenham uma fachada de adequação às normas legais. Quanto às estratégias de aquisição de mais terras, observou-se que os produtores são capazes de organizar complexas formas de capitalização, centradas em maiores esforços no trabalho e na contenção de gastos, além da utilização de políticas públicas favoráveis e de práticas costumeiras. Os arranjos intra-familiares

\footnotetext{
${ }^{1}$ Prof. Dr. da Faculdade de Engenharia de Ilha Solteira (UNESP). Av. Brasil Centro, n. 56. Ilha Solteira (SP). Cx. Postal: 31. CEP: 15385-000. E-mail: lazaro@agr.feis.unesp.br ${ }^{2}$ Pesquisadora do Departamento de Ciências da Administração e Tecnologia do Centro Universitário de Araraquara - UNIARA. Prof ${ }^{a}$ Adjunta Aposentada da FCL/UNESP e Voluntária da UNESP, junto à FCF, Campus de Araraquara. Rua José F. Secondo, 146. Vila Velosa. CEP: 14806-045. Araraquara (SP) E-mail: verammcosta@uol.com.br
} 
e as formas de cooperação ligadas ao parentesco mais amplo também se mostraram importantes para a ampliação da propriedade.

Palavras-chave: estratégias fundiárias; agricultura familiar; região de S. José do Rio Preto-SP.

\section{JEL Classification: Q 15}

Abstract: The maintenance and/or expansion of land form the central axle along which family farming organize their livelihood and work.. This paper analyzes these producers' strategies that are related to division of inheritance and succession, and the forms of acquisition of new areas. The survey on the characteristics of families and property was carried out by a questionnaire in 89 familiar producers of three cities of São José do Rio Preto (SP) region. Next, one third of those answering the questionnaire were interviewed in the same cities. The analysis of agrarian strategies showed a great diversity in the manner of inheritance sharing and conducting succession; although being basically supported in both processes by traditional rules they seem to follow the legal the legal rules. Regarding to acquisition strategies of more land, it was noticed that producers are able to organize complex forms of capitalization, which are centralized in bigger efforts at work and containment of expenses, besides the use of favorable public policies and customary practices. The intra-familiar arrangements and the forms of kinship cooperation also appeared as equally important to the property expansion.

Key Words: agrarian strategies; family farmer; São José do Rio Preto (SP) region.

JEL Classification: Q 15

\section{Apresentação}

Este artigo analisa as estratégias a que produtores familiares recorrem para manter e ampliar a área de terra sob o domínio da família, particularmente as estratégias relacionadas à divisão de herança e à sucessão, 
e as formas que utilizam para aquisição de novas áreas, em três municípios da mesorregião de São José do Rio Preto (SP) ${ }^{3}$.

As estratégias dos produtores familiares pesquisados nos três municípios são numerosas e diversificadas. A hipótese considerada neste trabalho é de que o eixo central que norteia e dá coerência ao conjunto de estratégias desenvolvidas pela grande maioria das famílias, inclui como elemento essencial sua permanência na terra, na condição de produtores rurais, se não de todos, ao menos de parte de seus membros.

Utilizar-se-á a noção de estratégias e habitus ${ }^{4}$ conforme definido por Bourdieu (1983 e 1994) para interpretar o comportamento dos produtores que transita entre os ditames da tradição, as regras formais de divisão da herança e a racionalidade capitalista, para construir um sistema próprio de estratégias que busca assegurar seus objetivos de ampliação ou ao menos de manutenção da terra ligada à família.

Há uma dupla (in)determinação: as condições sociais, econômicas e políticas de um determinado contexto e o habitus influenciam decisivamente as estratégias utilizadas em termos de objetivos e em relação às finalidades efetivamente alcançadas. Mas nem tudo é mecanicamente determinado externamente ao sujeito; este também tem possibilidade de respostas ativas, ao mesmo tempo em que nem todas as ações/práticas desenvolvidas pelo sujeito têm uma finalidade consciente.

A organização da análise em torno do conceito de estratégias significa privilegiar as ações dos sujeitos na construção de suas trajetórias de

\footnotetext{
${ }^{3}$ Os resultados apresentados fazem parte de uma pesquisa mais ampla que teve como objetivo levantar e analisar a relação entre o modo de vida dos produtores familiares e as estratégias que se mostraram capazes de garantir, ao menos parcialmente, a reprodução social desses produtores, nas últimas décadas. Além das estratégias fundiárias, foram estudadas também a utilização de estratégias ligadas à produção e à comercialização; à gestão da unidade familiar; e estratégias de cooperação e organização entre diferentes unidades familiares (SANT'ANA, 2003).

${ }^{4}$ Bourdieu (1983) define habitus como algo adquirido e que assume "a forma de disposições permanentes", mas destaca também seu caráter histórico: "é um produto dos condicionamentos que tende a reproduzir a lógica objetiva dos condicionamentos, mas introduzindo neles uma transformação; é uma espécie de máquina transformadora que faz com que nós 'reproduzamos' as condições sociais de nossa própria produção, mas de maneira relativamente imprevisível, de uma maneira tal que não se pode passar simplesmente e mecanicamente do conhecimento das condições de produção ao conhecimento dos produtos". (BOURDIEU, 1983, p. 105)
} 
vida, mas sem desprezar os condicionantes e as limitações do contexto da sociedade envolvente e do processo histórico mais geral.

\section{Metodologia}

Em função do objetivo do trabalho, adotou-se como foco de investigação a área formada por três municípios da mesorregião de São José do Rio Preto-SP, nos quais a presença da propriedade familiar é marcante, mas com realidades diferentes em termos de alternativas agropecuárias adotadas. Os municípios escolhidos foram Marinópolis (Escritório de Desenvolvimento Rural - EDR - de Jales), Valentim Gentil (EDR de Votuporanga) e Jaci (EDR de S. José do Rio Preto).

Essa região, durante várias décadas do século XX, teve sua economia baseada na cafeicultura, desenvolvida não apenas em grandes fazendas, mas também com uma forte inserção de pequenos proprietários, muitos dos quais ex-colonos de café de fazendas localizadas em regiões de colonização mais antiga. Com a decadência do café ocorreu uma tendência de diversificação de culturas, com destaque para a bovinocultura de leite e corte, a citricultura e a fruticultura em geral.

A orientação seguida na seleção inicial dos produtores pesquisados foi baseada nos critérios do PRONAF (Programa Nacional de Fortalecimento da Agricultura Familiar) vigentes na época do levantamento de campo $(1999)^{5}$ : o produtor deveria possuir no máximo área de quatro módulos fiscais ${ }^{6}$ do município e trabalhar diretamente na área com a família ou utilizando a ajuda eventual de terceiros, podendo contar ainda com até dois empregados fixos. A principal fonte de renda do produtor também deveria ser proveniente da agropecuária. Além destes, esta pesquisa

\footnotetext{
${ }^{5}$ O caráter de orientação significa que foram incluídos produtores que, na época da pesquisa, não se enquadravam em um quesito, como área ou fonte de renda, mas que durante a maior parte de suas trajetórias atendiam àquelas condições. Os critérios atuais do PRONAF (safra 2004/2005) estabelecem a divisão dos produtores familiares em cinco diferentes segmentos, em função da renda bruta e da utilização ou não de mão-de-obra contratada, além de um segmento (Tipo A) ser exclusivo para assentados. Regras completas do Programa podem ser obtidas no site http://www.pronaf.gov.br.

${ }^{6}$ Módulo fiscal é uma unidade de medida expressa em hectares, fixada para cada município, e que estabelece a área mínima necessária à subsistência do produtor e sua família. Em Jaci e Valentim Gentil esta área é de 24ha e em Marinópolis de 22ha.
} 
adotou um critério adicional: o produtor deveria ter em torno de 30 anos de trabalho na agropecuária.

O levantamento das principais características dos produtores, de suas famílias e da propriedade, foi realizado por meio de um questionário aplicado junto a 27 produtores em Marinópolis, 29 em Jaci e 33 em Valentim Gentil, totalizando 89 produtores. Posteriormente foram realizadas entrevistas gravadas com um terço dos produtores de cada município, que haviam respondido ao questionário.

A aplicação do questionário e a realização das entrevistas foram feitas basicamente com o chefe da família - homem ou mulher -, mas em um número significativo de propriedades houve a participação de outros membros da família (pai, mãe, esposa(o), filhos e outros), no processo de coleta de informações.

\section{Algumas características gerais das famílias pesquisadas}

Os produtores pesquisados, em função do perfil que se buscou na pesquisa, apresentam idade avançada (média entre 57 e 61 anos) nos três municípios e estão na mesma área há cerca de três décadas. Em Valentim Gentil 94\% dos produtores moram na propriedade, enquanto em Marinópolis e Jaci este índice é de $77 \%$ e $68 \%$, respectivamente. (Tabela 01).

Tabela 1. Dados sobre o perfil dos produtores e o número médio de moradores, nos três municípios pesquisados.

\begin{tabular}{lccc}
\hline ITEM & Jaci & Valentim Gentil & Marinópolis \\
\hline No $^{\circ}$ total de produtores & 29 & 33 & 27 \\
Média de idade dos produtores (anos) & 59 & 57 & 61 \\
No médio de anos de trabalho na área atual $^{\text {o de produtores que moram na propriedade }}$ & 31 & 27 & 31 \\
Nountidade média de moradores & 20 & 31 & 21 \\
\hline
\end{tabular}

Fonte: Dados da pesquisa, 2000.

Em relação ao número médio de moradores nas propriedades, há uma relativa diferença entre Jaci (quatro) e os demais municípios (cinco). Em todos, porém, há grande variação em torno dessas médias: enquanto 
algumas famílias são compostas por dois integrantes, outras possuem mais de dez.

De modo geral, nos três municípios, o grau de instrução formal dos pais de família pesquisados é muito baixo, mas tem ocorrido uma evolução significativa da escolaridade dos membros da família. Quando se compara o grau de instrução dos pais com a escolaridade dos filhos, nota-se que a maior freqüência passou da quarta série do ensino fundamental (entre os pais) para o nível médio completo (entre os filhos). Essa evolução também ocorreu no sentido de produzir uma maior homogeneidade entre os três municípios pesquisados.

O fato do nível de escolaridade das esposas ser semelhante ao dos maridos sugere que o fator estrutural (falta de oferta de ensino em graus mais elevados) é que determinou a baixa escolaridade e não as diferenças de gênero. Por outro lado, quando se levanta o número de filhos do sexo masculino e feminino, observa-se que dentre os filhos que permanecem na propriedade há forte predominância de homens ${ }^{7}$. No total dos três municípios, são 86 homens (75\%) e apenas 28 mulheres (25\%), sendo que em Valentim Gentil a diferença é ainda mais acentuada (apenas $17 \%$ são mulheres).

Em Jaci as principais atividades desenvolvidas pelos produtores são a pecuária de leite, o cultivo da laranja e do café; em Valentim Gentil destacam-se a pecuária leiteira, a laranja, a manga e o café; e em Marinópolis a uva, a laranja e o limão são os produtos mais importantes, mas tem aumentado a área com outras frutas, como a banana maçã e a pinha.

Em termos de uso de tecnologia e produtividade das atividades, em Marinópolis $55 \%$ dos produtores atingem produtividade superior à média da região em pelo menos uma das atividades comerciais que desenvolvem. Já em Jaci apenas $17 \%$ e em Valentim Gentil 12\% suplantam a média regional, enquanto outros $42 \%$ e $30 \%$, respectivamente, atingem a média da região em, ao menos, uma das atividades desenvolvidas.

\footnotetext{
${ }^{7}$ Todos os filhos maiores de 14 anos foram incluídos nesta análise, mesmo os casados que viviam sob a administração do chefe da família.
} 


\section{Formas de divisão da herança e sucessão}

Os produtores familiares dos municípios estudados organizam diversos tipos de estratégias visando a ampliação ou manutenção da terra e ao mesmo tempo procuram bloquear ou eliminar os fatores que identificam como capazes de aumentar os riscos de perda desses bens.

Observou-se que os produtores pesquisados receberam a terra de acordo com um padrão de divisão da herança que levou em consideração mais os interesses de continuidade do grupo familiar enquanto produtores, do que as aspirações dos indivíduos, especialmente quando se tratava das mulheres ${ }^{8}$.

Vários trabalhos, no Brasil, discutem as formas adotadas pelo campesinato para a transmissão da herança (ou de forma mais ampla, pelos agricultores familiares). O minorato predominou entre os descendentes de italianos do Rio Grande do Sul (SANTOS, 1978; TEDESCO, 1999), entre a grande maioria dos colonos de origem alemã, estudados por Woortmann (1995), nesse mesmo estado e por Seyferth (1984) em Santa Catarina, assim como entre os produtores de diferentes origens étnicas (caipiras) pesquisados por Loureiro (1987) ${ }^{9}$. Em outras regiões constatase com maior freqüência a primogenitura e outros tipos de partilha com exclusão das mulheres (embora estas recebam formalmente um dote ou compensação), sendo essa a tradição mais comum dentre os produtores da região estudada no presente trabalho.

As transformações apontadas pelos referidos autores no período recente e as manipulações que sempre ocorreram em torno dos padrões de herança, para torná-los mais viáveis e seguros ${ }^{10}$, $\operatorname{confirma}$ a tese de

\footnotetext{
${ }^{8}$ Esse padrão de herança desigualitária é típico da família extensa e visa garantir a integridade do patrimônio e sua vinculação a um nome (SEYFERTH, 1984; WOORTMANN, 1995). Embora haja variação sobre qual(is) filho(s) será(ão) beneficiados, em praticamente todos os casos prevalece a exclusão parcial ou total das mulheres. No minorato é o filho varão caçula que herda a terra e na primogenitura é o filho mais velho, desde que constituam família.

${ }^{9}$ Lamarche (1998) mostra que além da influência cultural, os diferentes padrões de transmissão da herança em Ijuí (RS) estão relacionados também ao número de filhos e à situação econômica do produtor.

${ }^{10} \mathrm{Na}$ verdade busca-se inculcar determinadas características nos filhos desde pequenos, que correspondam ao seu futuro papel social, ou seja, tanto o casamento como o herdeiro
} 
Wolf (1976) de que as condições locais podem levar a modificações nas regras de herança, sendo que a disponibilidade de terras e as mudanças na sociedade envolvente (como a crescente individualização dos projetos de vida) exercem pressões contraditórias sobre as famílias e estas buscam se adaptar:

Hoje, porém, assim como as estratégias matrimoniais, os processos de herança são flexíveis, o que não necessariamente quer dizer que seguem regras costumeiras e, muito menos, do sistema jurídico. Os vários tipos, modelos e desvios de herança (indivisa, igualitária, divisível, diversidade de bens, etc.) não possuem normas claras; são adaptações de estratégias familiares num jogo em que se combinam elementos internos e externos (TEDESCO, 1999, p. 112-3).

As regras seguidas por ocasião da divisão da herança foram decisivas para muitos dos produtores familiares pesquisados, pois a maioria apoiou-se na terra recebida como herança para a construção do patrimônio atual, especialmente no período mais recente em que a aquisição de terras se tornou mais difícil.

Quase 60\%, dos chefes de famílias trabalhavam na propriedade rural dos pais e quase a totalidade destes últimos recebeu alguma herança na forma de terra dos pais ou, em freqüência bem menor, do sogro(a) ${ }^{11}$. Em vários depoimentos constata-se que eles também contribuíram na aquisição ou ampliação desse patrimônio, quando trabalhavam com os pais.

Quando indagados sobre a forma de divisão da herança, surge um mosaico de situações bastante distintas, mas a grande maioria das propriedades, onde as famílias moram, foi herdada pelo homem (chefe de família), o que indica concretamente um viés de gênero compondo a sucessão e possivelmente a divisão da terra.

são construídos (WOORTMANN, 1995). Moura (1978) observa que a escassez de terra levou as famílias a excluírem parte dos filhos (sexo masculino) da herança da terra, sendo que estes são escolhidos por sua maior aptidão para o estudo e são então preparados (com maior educação formal) para a migração definitiva para o meio urbano”.

${ }^{11}$ Trata-se de um percentual alto, pois Zangaro (2001) ao analisar agricultores familiares de diversos bairros de Londrina (PR) verificou que em média $24 \%$ tiveram acesso à terra por meio de herança e outros $15 \%$ combinaram herança e compra. 
Além das tradições culturais que dentre as famílias pesquisadas são muito variáveis, mesmo dentro de cada município, as características das propriedades e a sua evolução também são fatores fundamentais para entender o tipo de partilha adotado e as estratégias envolvidas na manutenção de um patrimônio construído ao longo de muitos anos de trabalho.

A Figura 1 traz, para os três municípios, a distribuição das propriedades $^{12}$, por estrato de área, dos produtores pesquisados. Essas áreas correspondem às terras que na época da pesquisa (2000) pertencia ao produtor, incluindo a parte recebida como herança e/ou aquelas que por ventura ele tenha adquirido por conta própria.

A análise dos dados indica que, especialmente em Valentim Gentil, para um grande número de unidades familiares é problemática a sua subdivisão, pois uma área menor que cinco hectares para gerar uma renda suficiente para a manutenção de uma família teria de ser ocupada por atividades intensivas em capital ou trabalho (olericultura por exemplo) ${ }^{13}$.

Figura 1. Distribuição das propriedades (área total de cada produtor) por estrato de área, nos três municípios. Fonte: Dados da pesquisa, 2000.

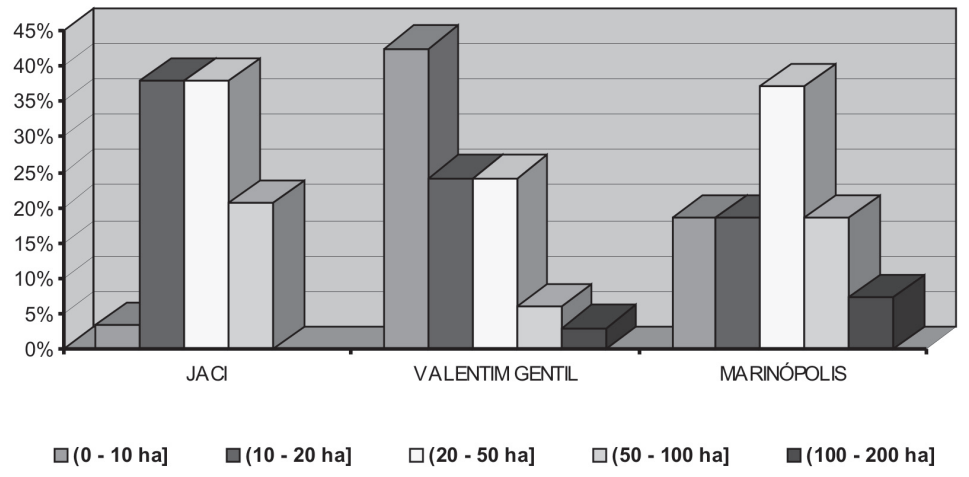

\footnotetext{
12 Trata-se da soma das áreas de todas as propriedades que o produtor possui. Não inclui áreas arrendadas.

${ }^{13}$ Seyferth (1984) estudando “colonos-operários” do Vale do Itajaí (SC), que combinam sua ocupação na agricultura com o trabalho na indústria têxtil, mostra que a estrutura fundiária composta por propriedades muito pequenas (62,5\% menores do que 10 ha) é um fator importante para explicar esse fenômeno, pois essas áreas não garantem renda suficiente para a subsistência da família, gerando vários não herdeiros (que, no entanto, podem continuar a morar e, quase sempre, obter alguns produtos de sua subsistência do quintal/horta).
} 
Por outro lado, como vários desses produtores eram colonos, parceiros e posseiros (cerca de $35 \%$,), trata-se de uma geração que não possuía terras e construiu um certo patrimônio fundiário, embora nem sempre suficiente para garantir a reprodução social da família enquanto produtores rurais. Deve-se ressalvar ainda que os destinos dessas propriedades não estão definidos e nem todas estão em situação precária.

Há uma tendência da divisão da herança ser mais restritiva no caso de famílias com pouca terra em relação às que possuem uma área maior, embora não seja possível identificar um padrão para cada um desses grupos. Outros fatores acabam influenciando o tipo de divisão adotado, como o grau de autoridade paterna na imposição dos sucessores, o número de filhos de cada sexo, a tradição étnico-cultural da família em relação à herança, dentre outros. O que os resultados da pesquisa mostram é o esforço de manutenção do patrimônio nas mãos da família, embora se utilize uma grande diversidade de arranjos para concretizar esse intento.

A divisão mantendo o usufruto dos pais, geralmente regulariza situações pré-existentes. Na grande maioria dos casos esse usufruto é parcial ou significa concretamente apenas a obrigação de manutenção dos pais e de cobrir gastos monetários eventuais que suas aposentadorias não dão conta.

Quando os pais recebem o usufruto o fazem de uma ou duas atividades principais, sendo comum que a renda paga seja menor que a vigente na região. Há casos em que a redução é gradual:

[...] pagava no começo, no café nós pagava à meia, né, foi quando nós veio tocar café com ele [sogro] aí depois mais pra frente ele foi abaixando a renda pra nós, né, passou a quarenta...pagava quarenta pra ele e sessenta pra nós...depois, no fim foi baixando mais ainda, agora nós só paga vinte só, vinte por cento. Produtor $26(\mathrm{M})^{14}$.

Essa condição de não pagar renda ou de ser um parceiro privilegiado do próprio pai/sogro permitiu que muitas famílias construíssem seu próprio patrimônio.

\footnotetext{
${ }^{14}$ Para identificar os produtores foram utilizados números, seguidos da primeira letra de seus respectivos municípios
} 
No caso de divisão igualitária, aqueles que estão trabalhando na terra continuam explorando a área e, muitas vezes, compram as partes que caberiam aos irmãos que deixaram a propriedade precocemente (irmãs que casaram ainda adolescentes ou saíram para estudar; irmãos que mudaram de atividade, foram para propriedade do sogro ou construíram patrimônio próprio significativo). Essas aquisições evitam o excessivo parcelamento das propriedades e cumprem também a função de não entregar para "estranhos" o patrimônio que foi construído pela família e que tem um valor sentimental.

A compra dentro da família constitui-se em uma prática muito freqüente e quase sempre a aquisição é facilitada. Constataram-se casos em que o dinheiro saia do próprio trabalho na propriedade, além da ordem e o prazo de pagamento não ser fixo:

As heranças foi assim, nós foi comprando de nossas irmãs, aos poucos, né...eu e meu irmão compramos de minhas irmãs mesmo...então conforme nós vendia [a produção agrícola] ia pagando aquelas que precisavam primeiro, ia pagando...aquelas que davam um prazinho, nós ia trabalhando, tirando...o lucro, né. Produtor 08 (VG)

A venda da propriedade e a divisão sumária do dinheiro ocorrem quando a área é muito exígua e não permite parcelamento ou quando há grande vantagem econômica de vender a propriedade em bloco. Ocorre ainda quando o interesse da maioria dos herdeiros não é ter a terra e nenhum tem condições de adquiri-la individualmente.

Há situações em que apenas parte dos filhos continua a trabalhar em conjunto com os pais e, a partir de certo momento, a família começa adquirir outras propriedades que são registradas no nome desses filhos ou então, por ocasião da transmissão da herança, a terra é dividida somente entre os filhos que supostamente contribuíram de maneira efetiva na edificação do patrimônio. É uma forma de deslegitimar o sistema de herança consangüínea e valorizar a herança em função do trabalho realizado:

[...] de treze irmãos que nós era, foram casando, foram saindo, cuidando de suas vidas, né. Ficamos só cinco aqui, eu que sou o 
caçula, né, hoje com 62 anos de idade e os outros quatro irmãos. Aí um dos irmãos resolveu vender e ir pro Mato Grosso, então foi repartido, o meu pai repartiu pros cinco que estava aqui...porque os outros, do anterior, já tinha saído antes, quando nós não tinha nada ainda, então isto foi adquirido foi depois disso, né, depois que os mais velhos saíram. No momento que nós estava aqui, o meu pai achou por bem deixar os 20 alqueires pros cinco que estava aqui, os outros de fora não teve nenhuma objeção, porque viu a situação, foi nós que praticamente ganhamos este pedaço de terra... Produtor 06 (VG)

É comum, no entanto, esse procedimento estar ligado ao viés patrilinear da divisão do patrimônio e a preconceitos contra a mulher: seu trabalho não é valorizado quando solteira, pois mesmo que esteja trabalhando com a família (mais ainda se a atividade for somente no âmbito doméstico), essas áreas são registradas no nome dos irmãos (homens), e ao casar freqüentemente não lhe oferecem oportunidade para continuar com o marido na área.

A justificativa para a exclusão das mulheres na divisão da terra é baseada no argumento de que elas, ao casar, estarão supostamente recebendo o patrimônio herdado pelos maridos, ocorrendo o que Woortmann (1995), denomina de circulação de mulheres e imobilidade da terra ${ }^{15}$. A terra é vista como um patrimônio que deve ser mantido pela família, pois é só o homem que "carrega” o nome da família.

Em um contexto marcado pela escassez de terra e recursos, as estratégias de divisão da herança visam a manutenção apenas de parte dos filhos na propriedade, mas de forma viável em termos de produção e renda; isto é realizado pela ética do trabalho que exclui da sucessão aqueles que não participaram da construção/ampliação do patrimônio e pela criação de outras alternativas de reprodução social, mesmo que desiguais, para os não herdeiros (dote, estudo).

\footnotetext{
${ }^{15}$ Pois mesmo quando a mulher formalmente recebe sua parte na herança em terra, esta é incorporada à terra que o marido já possui. Tedesco (1999) menciona que nas entrevistas os maridos referiam-se a estas terras como se fossem deles apenas e só quando a mulher estava presente explicitavam que tratava-se de herança da esposa.
} 
Algumas famílias, conscientes das dificuldades de construir em conjunto um patrimônio significativo, criaram uma situação de relativa autonomia para os filhos solteiros (ou recém-casados), de modo que estes pudessem construir seu patrimônio próprio, seja por meio da redução/eliminação do percentual pago ao conduzir atividade dentro da propriedade ou ajudando-os no arrendamento de outras áreas.

Até meados da década de 80, a ajuda na edificação desse patrimônio visava, na maioria dos casos, a aquisição de terras e, no período mais recente, em função da elevação do valor da terra e do maior grau de instrução dos filhos, este auxílio é dirigido para a criação de opções de trabalho autônomo fora da agricultura, como construção de casas, abertura de um negócio ou compra de um bem. A evasão dos filhos para trabalharem como empregados em outros setores tem sido motivada também por outros fatores, como a insatisfação com a remuneração obtida na agricultura, à penosidade e à imagem negativa do trabalho agrícola ${ }^{16}$.

\section{Estratégias de aquisição de novas áreas}

No estudo comparativo coordenado por Lamarche (1998) os produtores familiares brasileiros se destacaram pelo desejo de obterem/adquirirem mais terra ${ }^{17}$ em relação aos produtores dos demais países incluídos naquela pesquisa (Polônia, Canadá, França e Tunísia). Essa demanda pode estar ligada à insuficiência de terras e às restrições impostas a esses produtores quando buscam ter acesso a outras áreas. Trata-se de uma característica marcante da formação social brasileira e que colocou sempre grande parte dessa categoria social em luta contra o que Wanderley (1995) denomina bloqueio fundiário.

\footnotetext{
${ }^{16}$ Silvestro et al. (2001) mostram que no caso do oeste de Santa Catarina, essa imagem é recorrente especialmente no caso das filhas. Ao mesmo tempo, observou-se que uma parte dos herdeiros sente-se prejudicada nas situações de crise, pois precisaram deixar o estudo mais cedo e não estão preparados para enfrentar a competição do mercado de trabalho urbano.

${ }^{17}$ Em torno de $89 \%$ dos produtores pesquisados no Brasil manifestaram interesse de ampliar sua área terra, sendo que $65 \%$ haviam conseguido e continuavam dispostos a manter o ritmo de expansão; enquanto $24 \%$ sonhavam com superfícies maiores, mas não se dispunham a vender a propriedade para comprar outra maior em outra região (LAMARCHE, 1998).
} 
A modernização técnico-produtiva do campo brasileiro, intensificada a partir do final dos anos 60, como já foi destacado em vários trabalhos (GRAZIANO DA SILVA, 1982; MARTINE, 1989; PALMEIRA, 1989), teve um caráter desigual e excludente, pois beneficiou mais as regiões sudeste/ sul, alguns tipos de produtores (grandes) e culturas (exportáveis e insumos agroindustriais) em detrimento de outros e não alterou a estrutura fundiária que historicamente sempre foi muito concentrada. No período recente, embora os índices técnicos da produção tenham se alterado de forma significativa, não houve modificações relevantes na estrutura fundiária e nem redução das desigualdades sociais e regionais ${ }^{18}$.

Os produtores familiares e os trabalhadores sem terras, no entanto, também desenvolveram estratégias que buscaram enfrentar essas restrições de acesso à terra, seja por meio dos movimentos sociais engajados na luta pela reforma agrária, seja utilizando estratégias familiares ou ligadas a grupos de parentesco e afinidade, visando a manutenção ou ampliação de suas áreas de trabalho.

Wanderley (1995) destaca que o acesso à terra é o eixo central das estratégias dos produtores e de suas famílias. Seus projetos de vida se expressam tanto na recusa de vender a terra, como no desejo de comprar mais terra e deixá-la aos seus sucessores. Esse esforço para aquisição e ampliação da terra esteve presente nos projetos e/ou sonhos de quase todas as famílias pesquisadas.

Na Figura 2, estão expressos os resultados de uma análise da evolução das áreas por produtor pesquisado e por município. As modificações referem-se ao período entre o início das atividades de cada produtor (definido como o momento em que este recebe de herança ou adquire a terra, tornando-se um produtor autônomo) e a época da pesquisa.

Observa-se que em Marinópolis quase $60 \%$ dos produtores pesquisados conseguiram ampliar sua área e nenhum teve redução de área. Em Valentim Gentil 39,3\% não tiveram alteração nenhuma desde o início de suas atividades, enquanto 48,5\% aumentaram e $12,1 \%$ sofreram

\footnotetext{
${ }^{18}$ De acordo com Bastos (2002), o Brasil apresenta produtividade e custos de produção semelhantes aos Estados Unidos e outros países do primeiro mundo, em algumas culturas e atividades (como soja, milho, frango e carne suína). Enquanto Gonçalves (1999) mostra que mesmo com a elevação da produtividade média persistem diferenças extremas de produtividade entre os produtores e regiões.
} 
redução de suas áreas. Em Jaci apenas 6,9\% dos produtores tiveram perda de área, $44,8 \%$ tiveram acréscimo e quase a metade, $48,3 \%$, não apresentaram alteração de área.

Figura 2. Evolução das áreas por produtor, entre o início das atividades e a época da pesquisa, por município. Fonte: Dados da pesquisa, 2000.

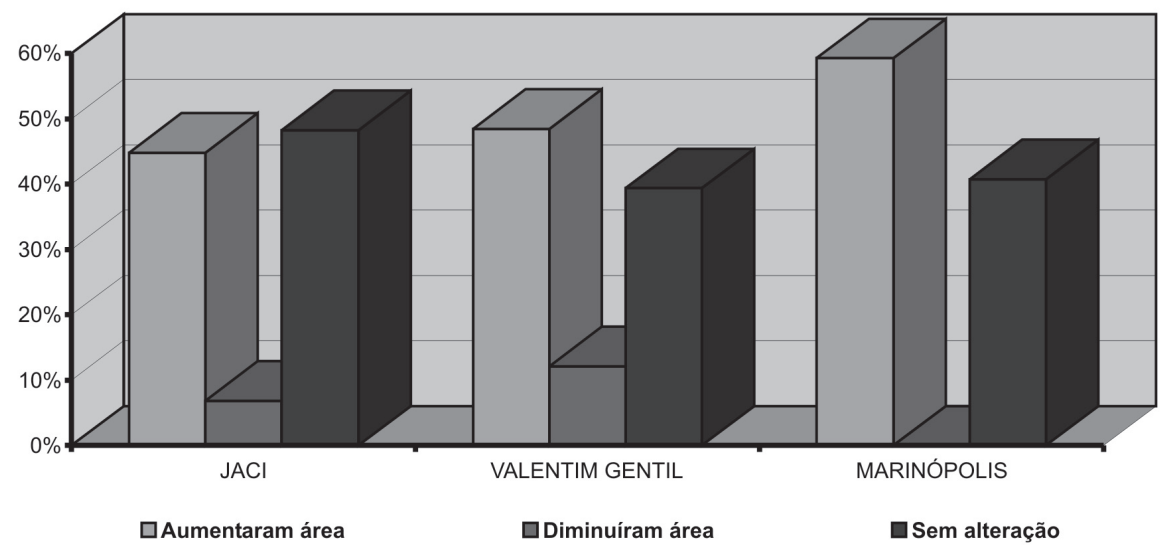

Quando a comparação é realizada entre a geração atual e a anterior, observa-se que metade dos produtores possui uma área menor do que aquela que os seus pais conseguiram acumular, embora possa ter ampliado a área que recebeu na forma de herança. Outros $43 \%$ superaram a área adquirida pelos pais e só $7 \%$ possuem área idêntica. Jaci é o município em que houve maior número de produtores com redução de área $(70 \%)$.

Este resultado indica que, embora de forma seletiva, uma parte dos produtores familiares tem conseguido criar as condições mínimas de sua reprodução. A observação de campo permitiu constatar também que parte da incorporação de área observada ocorreu por meio da compra de pequenas parcelas de outros herdeiros ${ }^{19}$ ou vizinhos que estavam em dificuldade e não tinham condições de manter a propriedade, ou seja, eliminando-se uma outra propriedade familiar (potencial ou já estabe-

${ }^{19}$ Como foi visto, em muitos casos, a aquisição das áreas de outros herdeiros é uma maneira encontrada pela família para que ao menos parte desta continue se reproduzindo enquanto produtores rurais, em função das pequenas dimensões da terra que possuem. 
lecida). Esses produtores entrevistados são, em certa medida, aqueles que conseguiram vencer a dura luta contra a expropriação $0^{20}$.

A aquisição de terras ocorreu por meio de um acúmulo gradual de pequenas economias durante um período relativamente extenso ou em função de uma colheita bem sucedida em termos de quantidade e preço. A ampliação do patrimônio também se deu em função da mudança de atividades. Nesse caso muitos dos produtores foram influenciados pelas idéias dos filhos ou contaram com o apoio destes.

Na época de abertura da fronteira agrícola na região, até os anos 50 ou 60, muitos produtores venderam pequenos sítios/chácaras ou, ao reunirem algum montante em dinheiro, buscaram entrar mais para o interior, onde conseguiam comprar áreas maiores de terra.

Constatou-se que, de modo geral, a compra da primeira propriedade é precedida por um período de intensificação do trabalho, seja aumentando a área cultivada com café (quando parceiro), plantando roças (milho, algodão ou arroz) fora da propriedade do pai (embora quase sempre ajudado por este com o empréstimo de máquinas e equipamentos) ou cultivando roça na própria propriedade onde trabalhava como parceiro.

Quanto ao processo de aquisição, aqueles que ocorreram nas décadas de 1960 e 1970 foram baseados em costumes da época, com parcelamento do pagamento, sem qualquer tipo de correção monetária ou juros, em função de colheitas futuras. O prazo às vezes se estendia por dois ou três anos e a própria produção na área acabava formando o capital necessário para o pagamento das parcelas vincendas:

Eu comprei em junho este sítio... então eu dei duzentos contos, aquela época, mais duzentos em setembro, aí vendi boi, tive que vender tudo, fiquei só com um cavalo (...) Tinha comprado por mil e duzentos contos de reis, fiquei devendo oitocentos para pagar quatrocentos dali um ano e quatrocentos em dois anos...

\footnotetext{
${ }^{20}$ Calcula-se que o êxodo rural de 1960-80 atingiu cerca de 28 milhões de pessoas, mas Mueller \& Martine (1997) mostram que na década de 1980 o ritmo do êxodo rural havia arrefecido em relação à década anterior e se concentrado nas regiões mais dinâmicas em termos de modernização. Na década de 1990, 4 milhões de pessoas deixaram de residir na área rural e foram para as cidades, mas havia ainda um contingente de quase 32 milhões de pessoas no campo (18,8\% da população brasileira em 2000) (FIBGE, 2000).
} 
Pagando juro que era micharia. Só que Deus me ajudou, que no primeiro ano se eu quisesse teria pago tudo, eu não paguei porque ele [ex-proprietário] não quis receber...Tinha três mil e seiscentos pés de café e ele deu no primeiro ano 400 sacos, colhi também 105 sacos de arroz, então dava pra mim ter pagado os oitocentos contos naquela época, mas ele não quis...então eu paguei quatrocentos no segundo ano e no terceiro ano paguei mais quatrocentos. Produtor 22 (VG)

Aquisições mais recentes, a partir dos anos 80, na maioria dos casos foram à vista ou com um prazo curto para pagamento. Tanto comprador como vendedor temiam (e ainda temem) o efeito da inflação e as incertezas ligadas aos preços.

Observou-se outra estratégia utilizada por vários produtores que demonstra a importância que a aquisição de mais terras tem para estas famílias: ao saberem de um negócio considerado vantajoso, sem que tivessem recursos para comprar a área total, recorriam a irmãos, compadres e amigos. A associação de membros de famílias extensas, especialmente irmãos, mas também entre compadres, em vários casos contribuiu para potencializar a capacidade da família em adquirir novas áreas, como relata um produtor de Marinópolis:

[...] o que a gente tem....foi ganhado assim, porque sozinho é duro, você não consegue comprar nada hoje sozinho, você tem que ter união, né, então você tem dinheiro, por exemplo, nós tinha dinheiro pra comprar dez alqueires, se eu fosse comprar sozinho eu não podia, se reunia os quatro [irmãos]..., um pouquinho de um, um pouquinho de outro, você já comprava, você já adquiria uma área, né, hoje não, então a gente tendo, por exemplo, união com a família assim, você tem mais força, né...é que nem qualquer empresa, um sozinho é uma coisa, mas com a força de outra...se torna mais fácil até pra trabalhar, né!. Produtor 14 (M)

O trabalho nessas áreas tanto podia ser comum com divisão da renda (caso mais freqüente entre irmãos e cunhados) ou a separavam informalmente e cada um a explorava como lhe conviesse. Os impos- 
tos e outros gastos eventuais eram divididos. A manutenção formal da sociedade às vezes era compulsória, até que um dos sócios resolvesse vender para o outro, pois as áreas eram tão pequenas que não podiam ser desmembradas legalmente.

Uma análise geral dos períodos em que ocorreram as ampliações das propriedades, indica que a partir de meados da década de 1980 houve uma redução das aquisições, devido às mudanças na sistemática de pagamento e possivelmente em função de uma maior valorização das terras ${ }^{21}$ em relação às receitas líquidas obtidas pelos produtores, pois além da elevação dos custos de produção, ampliaram-se também as despesas monetárias das famílias. Um produtor foi categórico: "hoje com dinheiro de propriedade não compra outra propriedade, só quem tem outro ramo de negócio” (Produtor 07-J ).

\section{Considerações finais}

A análise das estratégias fundiárias mostrou uma grande diversidade nos tipos de partilha da herança e de sucessão e que estas são apoiadas, basicamente, em regras tradicionais, embora mantenham uma fachada de adequação às normas legais.

A necessidade crescente de aumentar a produtividade e a escala de produção para se manterem competitivos em algumas explorações; as dimensões reduzidas da terra em relação ao número de herdeiros e os parcos recursos disponíveis para investir na produção, são fatores que têm levado os produtores a reproduzirem ou adaptarem regras desigualitárias de divisão da herança, excluindo parte dos herdeiros da divisão efetiva da terra. A ética do trabalho (só tem direito à herança aqueles que contribuíram na construção do patrimônio, ou seja, participaram diretamente do trabalho agrícola), enquanto justificativa moral adotada pelos produtores, ao mesmo tempo em que deslegitimiza a herança consangüínea automática, tem também um caráter ideológico de gêne-

\footnotetext{
${ }^{21}$ Esse período foi caracterizado pela vigência de vários planos econômicos que aumentaram a liquidez da terra e provocaram a elevação real do seu preço. Reydon et al. (2003) mostram que os preços das terras, embora tenham sofrido uma redução após o Plano Real, continuaram em patamares semelhantes aos de vários estados norte-americanos e muito superiores aos de outros países sul-americanos.
} 
ro, ligado à tradição patrilinear dos produtores familiares, que tende a excluir as mulheres da divisão da terra, mesmo quando formalmente a divisão dos bens foi igualitária.

A herança desigualitária e sua ligação com a preservação do patrimônio da família, enquanto um habitus presente no pensamento e na ação deste grupo de produtores, nem sempre assume a forma de uma estratégia consciente e racional. Muitas vezes não é necessário que o chefe da família exclua herdeiros, o habitus familiar leva os(as) filhos(as) a promoverem sua "auto-exclusão" quando deixam a unidade familiar e buscam outras ocupações. A grande maioria desses filhos que sai, também se sente desobrigada de continuar contribuindo na manutenção da família e aceita sua exclusão (parcial ou total) da herança. ${ }^{22}$

As estratégias visando a aquisição de mais terras revelaram que os produtores familiares possuem um aguçado senso empreendedor. São capazes de organizar complexas formas de capitalização, centradas em maiores esforços no trabalho e na contenção de gastos, além da utilização de políticas públicas favoráveis (como os subsídios da década de 1970) e de práticas costumeiras (como parcelamento do pagamento em dois ou três anos). Ao mesmo tempo organizam arranjos intra-familiares e formas de cooperação ligadas ao parentesco mais amplo (envolvendo parentesco consangüíneo de diferentes unidades familiares e relações tradicionais, como o compadrio) para conseguirem viabilizar a ampliação da propriedade. Para a grande maioria dos produtores pesquisados essas estratégias viabilizaram a compra, a manutenção ou mesmo a ampliação da propriedade.

Em muitos casos o esforço de manutenção ou ampliação da terra não objetiva apenas aumentar a área que será repassada aos filhos, para manter viável a propriedade, do ponto de vista produtivo, mas se reveste também de aspectos afetivos relacionados a um lugar que guarda as reminiscências da construção daquele patrimônio e envolve a preocupação com o destino que será dado a cada pedaço daquele chão.

\footnotetext{
${ }^{22}$ Woortmann (1995) constatou fato semelhante entre os produtores de Sergipe que, para herdarem a terra deviam combinar o critério de nascimento no local, com a residência e trabalho.
} 


\section{Referências bibliográficas}

BASTOS, G. S. Grãos: a produção sul-americana. Agroanalysis, Rio de Janeiro, v. 22, n. 4, p. 20-27, 2002.

BOURDIEU, P. Questões de sociologia. Rio de Janeiro: Marco Zero, 1983. 208p.

Stratégies de reproduction et modes de domination. Actes de la Recherche en Scienses Sociales, Paris, nº 105, p. 3-12, 1994.

BRASIL. Ministério do Desenvolvimento Agrário. Programa Nacional de Fortalecimento da Agricultura Familiar. Disponível em: http://www. pronaf.gov.br , acesso em: nov. 2002.

FUNDAÇÃO INSTITUTO BRASILEIRO DE GEOGRAFIA E ESTATISTICA (FIBGE). Censo demográfico de 2000, Brasil. Rio de Janeiro (RJ): FIBGE.

GONÇALVES, J. S. Mudar para manter: pseudomorfose da agricultura brasileira. São Paulo: CSPA/SAA, 1999. 373p.

GRAZIANO DA SILVA, J. A modernização dolorosa - estrutura agrária, fronteira agrícola e trabalhadores rurais no Brasil. Rio de Janeiro: Zahar, 1982. 192p.

LAMARCHE, H. (Coord.) A agricultura familiar: do mito à realidade. Campinas: Ed. da UNICAMP, v. 2, 1998, 348p.

LOUREIRO, M. R. G. Terra, família e capital: formação e expansão da pequena burguesia rural em São Paulo. Petrópolis (RJ): Vozes, 1987. $182 p$.

MARTINE, G. Fases e faces da modernização agrícola brasileira. Planejamento e Políticas Públicas, Brasília (DF), v. 1, 1989.

MOURA, M. M. Os herdeiros da terra. São Paulo: Hucitec, 1978. 100p.

MUELLER, C. C.; MARTINE, G. Modernização da agropecuária, emprego agrícola e êxodo rural no Brasil - A década de 1980. Revista de Economia Política, São Paulo, v. 17, n. 3, p. 85-104, 1997.

PALMEIRA, M. Modernização, Estado e questão agrária. Estudos Avançados, São Paulo, v. 3, n. 7, p. , 1989. 
REYDON, B. P. et al. Aspectos da questão agrária brasileira: lições à luz do mercado de terras. Projeto de Cooperação Técnica INCRA/FAO. Disponível em http://www.dataterra.org.br . Acesso em 20 jan. 2003.

SANT’ANA, A. L. Raízes na terra: as estratégias dos produtores familiares de três municípios da mesorregião de São José do Rio Preto (SP). Araraquara, 2003. 246p. Tese (Sociologia) Faculdade de Ciências e Letras, Universidade Estadual Paulista.

SANTOS, J. V.T. Colonos do vinho. São Paulo: Hucitec, 1978. 182 p.

SEYFERTH, G. Camponeses ou operários? O significado da categoria 'colono' numa situação de mudança. Revista do Museu Paulista, São Paulo, v. 29, p. 73-96, 1984.

SILVESTRO, M. L. et al. Impasses sociais da sucessão hereditária na agricultura familiar. Florianópolis (SC) - Brasília: Epagri; - NEAD/MDA, 2001. 102p.

TEDESCO, J. C. Terra, trabalho e família: racionalidade produtiva e ethos camponês. Passo Fundo: EDIUFP, 1999. 325p.

WANDERLEY, M. N. B. A agricultura familiar no Brasil: um espaço em construção. Reforma Agrária, Campinas, v. 25, n. 2/3, p. 37-57, 1995.

WOLF, E. R. Sociedades camponesas. 2. ed., Rio de Janeiro: Zahar, 1976. 150 p.

WOORTMANN, E. F. Herdeiros, parentes e compadres. São Paulo-Brasília: Hucitec/Edunb, 1995. 336p.

ZANGARO, L. C. M. A agricultura familiar em Londrina: um olhar sobre a diversidade. Campinas, 2001. 150p. Dissertação (Mestrado em Sociologia) - Instituto de Filosofia e Ciências Humanas, Universidade Estadual de Campinas. 